\title{
EKSTRAKSI EVENT BERBASIS PARAGRAF DARI ARTIKEL BERITA BAHASA INDONESIA
}

\author{
Masayu Leylia Khodra \\ Sekolah Teknik Elektro dan Informatika, \\ Institut Teknologi Bandung \\ masayu@stei.itb.ac.id
}

\author{
Yudi Wibisono \\ Ilmu Komputer, \\ Universitas Pendidikan Indonesia \\ yudi@upi.edu
}

\begin{abstract}
ABSTRAK
Dengan banyaknya artikel berita online yang terbit setiap saat, sistem ekstraksi event dapat membantu pembaca berita dengan memberikan informasi terstruktur dari setiap artikel berita. Ekstraksi event dari artikel berita merupakan proses mendapatkan informasi terstruktur 5 WIH yaitu siapa (who) melakukan apa (what), kapan (when), dimana (where), mengapa (why), dan bagaimana (how). Ekstraksi 5 Wl H ini merupakan salah satu jenis ekstraksi informasi. Model ekstraksi 5 Wl H dibangun dengan pendekatan berbasis sequence labeling berbasis skema BIO (Begin Inside Outside). Karena setiap paragraf berisi satu pokok pikiran, idealnya satu instans frame 5 WI H dihasilkan dari satu paragraf, dan satu artikel berita direpresentasikan dengan sejumlah instans frame $5 \mathrm{Wl} \mathrm{H}$. Oleh karena itu, makalah ini membahas pembangunan model ekstraksi event 5 WIH berbasis paragraf. Pemodelan dilakukan dengan meng gunakan korpus 610 teks paragraf yang diambil dari 57 artikel berita yang telah dianotasi secara manual dengan informasi $5 \mathrm{WlH}$. Pemodelan memanfaatkan arsitektur bidirectional LSTMs (long short term memory) dan CRF (conditional randomfields). Pada tahap evaluasi, kinerja model yang dicapai adalah F1 0.62 .
\end{abstract}

Kata Kunci: ekstraksi event, 5W1H, pembelajaran mesin, LSTMs, CRF

\section{PENDAHULUAN}

Berdasarkan hasil survei 2017 dari Asosiasi Penyelenggara Jasa Internet Indonesia, 57.13\% dari 143,26 juta pengguna internet Indonesia membaca artikel berita online sebagai gaya hidup (APJII, 2018). Walaupun begitu, banyaknya berita yang tersedia membuat pengguna sering terlewat event utama berita karena 2/3 kontennya diabaikan (Graber, 1984). Berbagai aplikasi berkembang untuk membantu pembaca berita mendapat informasi sebanyak mungkin, misalnya sistem agregasi berita, sistem peringkasan berita, atau sistem ekstraksi informasi. Sistem ekstraksi event merupakan salah satu jenis sistem ekstraksi informasi yang mengidentifikasi events pada teks tidak terstruktur, dan menghasilkan informasi terstruktur event berupa $5 \mathrm{~W} 1 \mathrm{H}$, yaitu siapa (who) melakukan apa (what), kapan (when), dimana (where), mengapa (why), dan bagaimana (how).
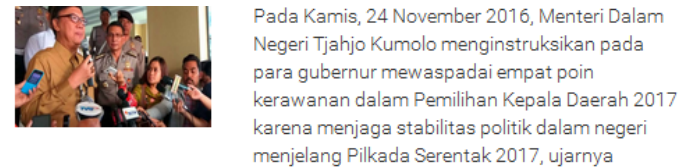

Pada Kamis, 24 November 2016, Menteri Dalam Negeri Tjahjo Kumolo menginstruksikan pad para gubernur mewaspadai empat poin kerawanan dalam Pemilihan Kepala Daerah 2017 karena menjaga stabilitas politik dalam negeri menjelang Pilkada Serentak 2017, ujarnya

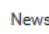

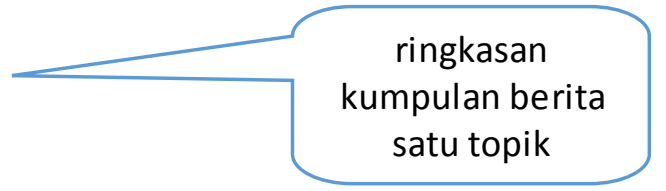

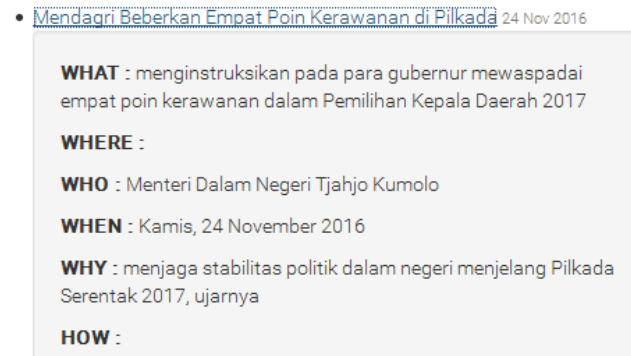

hasil ekstraksi event $5 \mathrm{~W} 1 \mathrm{H}$ 
Gambar 1 menunjukkan contoh luaran frame $5 \mathrm{~W} 1 \mathrm{H}$ dari sistem ekstraksi event $5 \mathrm{~W} 1 \mathrm{H}$ pada sistem agregasi berita berbahasa Indonesia (Khodra, 2016). Pada sistem ini, kumpulan artikel berita dikelompokkan untuk mendapatkan topik berita, lalu setiap artikelnya dianalisis untuk mendapatkan informasi event $5 \mathrm{~W} 1 \mathrm{H}$, dan informasi $5 \mathrm{~W} 1 \mathrm{H}$ dari setiap artikel dipakai untuk membuat ringkasan. Penelitian yang ada sebelumnya (Wang dkk, 2010; Khodra, 2015) mendefinisikan satu frame informasi $5 \mathrm{~W} 1 \mathrm{H}$ untuk satu artikel, sehingga hasil ekstraksi hanya memberikan satu informasi event utama dari artikel. Akibatnya, banyak informasi penting lain yang hilang.

Pada makalah ini, satu frame informasi 5W1H merepresentasikan informasi dalam paragraf, sehingga informasi satu artikel berita berupa beberapa frame $5 \mathrm{~W} 1 \mathrm{H}$. Berikut adalah contoh paragraf dan hasil ekstraksi frame 5W1H (lihat Gambar 2).

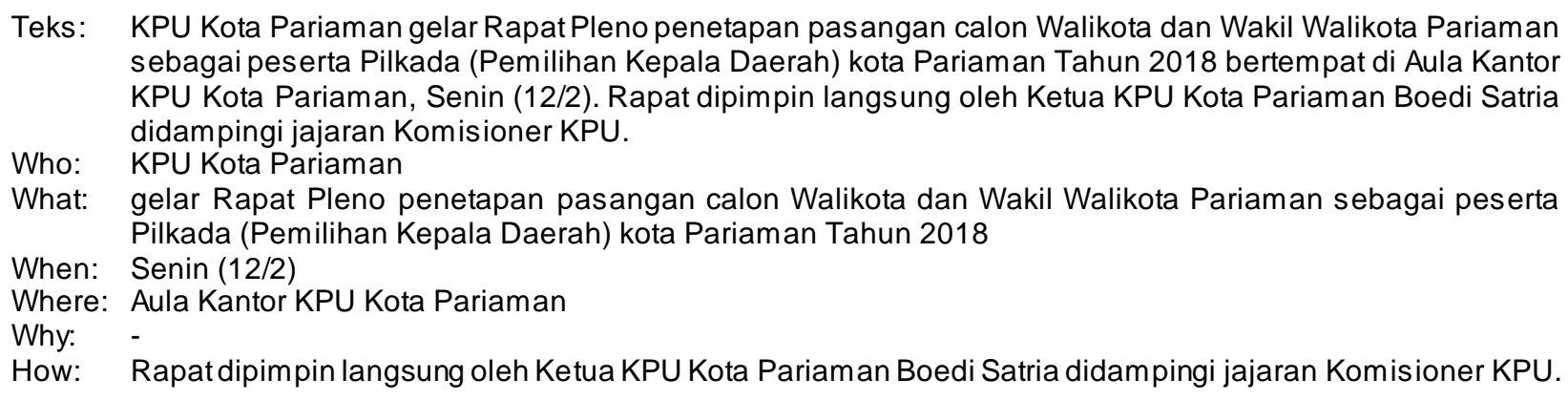

Teks: KPU Kota Pariaman gelar Rapat Pleno penetapan pasangan calon Walikota dan Wakil Walikota Pariaman sebagai peserta Pilkada (Pemilihan Kepala Daerah) kota Pariaman Tahun 2018 bertempat di Aula Kantor KPU Kota Pariaman, Senin (12/2). Rapat dipimpin langsung oleh Ketua KPU Kota Pariaman Boedi Satria didampingi jajaran Komisioner KPU.

Who: KPU Kota Pariaman

What: gelar Rapat Pleno penetapan pasangan calon Walikota dan Wakil Walikota Pariaman sebagai peserta Pilkada (Pemilihan Kepala Daerah) kota Pariaman Tahun 2018

When: Senin (12/2)

Where: Aula Kantor KPU Kota Pariaman

Why:

How: Rapat dipimpin langsung oleh Ketua KPU Kota Pariaman Boedi Satria didampingi jajaran Komisioner KPU.

Gambar 2.Contoh teks dari suatu paragraf berita dan frame 5W1H

Makalah ini bertujuan untuk menganalisis korpus 5W1H yang dianotasi manual, dan mengembangkan model ekstraksi event $5 \mathrm{~W} 1 \mathrm{H}$ dari teks paragraf berbasis pembelajaran mesin. Pada bagian selanjutnya, akan dibahas konsep ekstraksi event. Bagian 3 akan membahas hasil pemodelan. Pada bagian terakhir, akan dibahas konklusi dan penelitian selanjutnya yang akan dilakukan.

\section{KONSEP EKSTRAKSI EVENT}

Pendekatan umum untuk ekstraksi informasi ada dua yaitu pendekatan berbasis aturan dan pendekatan berbasis pembelajaran mesin. Dalam pendekatan berbasis aturan, peneliti mendefinisikan sejumlah aturan ekstraksi secara manual. Teks masukan akan diinferensi secara otomatis dengan menggunakan aturan ekstraksi tersebut, dan hasil akhir inferensi aturan ini merupakan hasil ektraksi informasi. Pendekatan ini dapat memberikan kinerja yang baik pada domain yang spesifik, tetapi sulit diterapkan pada domain yang lebih luas dan butuh waktu dan biaya lebih besar (Jiang, 2012).

Pendekatan berbasis pembelajaran mesin lebih banyak digunakan saat ini. Pendekatan ini mempelajari korpus berlabel, dan mentransformasikan ekstraksi event sebagai persoalan sequence labeling. Suatu teks masukan dianggap sebagai sekuens token $t=\left(t_{1}, t_{2}, \ldots, t_{n}\right)$ yang masing-masing token $t_{i}$ diberi label $\mathrm{y}_{\mathrm{i}}$. Sequence labeling mengasumsikan penentuan label yi tidak hanya bergantung pada token $\mathrm{t}_{\mathrm{i}}$, tetapi juga bergantung pada token lainnya dan label lainnya dalam sekuen tersebut. (Jiang, 2012)

Sama seperti Khodra (2015), makalah ini juga mengembangkan model sequence labeling dengan skema BIO (Begin Inside Outside) untuk ekstraksi event. Pada skema BIO, setiap slot informasi E memiliki dua label yaitu B-E (Begin E) yang menyatakan token awal dari informasi E, dan I-E (Inside E) yang menyatakan token dalam informasi E. Sebagai tambahan, terdapat satu label O (Other atau Outside) untuk token lainnya. Karena terdapat 6 slot informasi event pada frame $5 \mathrm{~W} 1 \mathrm{H}$, terdapat 13 label $(=2 * 6+1)$, yaitu beg_who, in_who, beg_what, in_what, beg_when, in_when, beg_where, in_where, beg_why, in_why, beg_how, in_how, and other. Setiap token dari teks masukan diklasifikasikan atau ditentukan labelnya ke salah satu dari 13 kelas yang didefinisikan ini.

Karena pendekatan ini memerlukan korpus berlabel, dilakukan tahap anotasi manual terhadap 610 teks paragraf dari 57 artikel berita politik. Contoh hasil anotasi manual dapat dilihat pada Gambar 2. Selanjutnya, setiap teks paragraf pada korpus berlabel ditransformasi menjadi sekuens token berlabel. 
Gambar 3 merupakan contoh sekuens token dari teks paragraf pada Gambar 2. Token dapat berupa kata atau tanda baca.

\begin{tabular}{|c|c|c|c|c|c|}
\hline KPU & B-Who & Pemilihan & I-What & $12 / 2$ & I-When \\
\hline Kota & I-Who & Kepala & I-What & ) & I-When \\
\hline Pariaman & I-Who & Daerah & I-What & & $\mathrm{O}$ \\
\hline gelar & B-What & ) & I-What & Rapat & B-How \\
\hline Rapat & I-What & kota & I-What & dipimpin & I-How \\
\hline Pleno & I-What & Pariaman & I-What & langsung & I-How \\
\hline penetapan & I-What & Tahun & I-What & oleh & I-How \\
\hline pasangan & I-What & 2018 & I-What & Ketua & I-How \\
\hline calon & I-What & bertempat & 0 & KPU & I-How \\
\hline Walikota & I-What & di & $\mathrm{O}$ & Kota & I-How \\
\hline dan & I-What & Aula & B-Where & Pariaman & I-How \\
\hline Wakil & I-What & Kantor & I-Where & Boedi & I-How \\
\hline Walikota & I-What & KPU & I-Where & Satria & I-How \\
\hline Pariaman & I-What & Kota & I-Where & didampingi & I-How \\
\hline sebagai & I-What & Pariaman & I-Where & jajaran & I-How \\
\hline peserta & I-What & & $\mathrm{O}$ & Komisioner & I-How \\
\hline Pilkada & I-What & Senin & B-When & KPU & I-How \\
\hline( & I-What & ( & I-When & . & I-How \\
\hline
\end{tabular}

Gambar 3.Contoh hasil transformasi teks paragraf menjadi sekuens token berlabel BIO

Selanjutnya kumpulan sekuens token ini akan menjadi input dari proses pembelajaran mesin. Secara umum, teknik pembelajaran mesin menerima data pembelajaran berupa kumpulan vektor fitur dan menghasilkan pola yang merepresentasikan aturan penentuan label dari setiap token teks masukan. Vektor fitur dapat merupakan fitur leksikal (contohnya kata, n-gram), fitur sintaksis (contohnya POS tag), fitur semantik (contohnya kedekatan kata), dan fitur pragmatis (contohnya posisi token). Penentuan set fitur yang digunakan untuk merepresentasikan suatu artikel atau dokumen disebut rekayasa fitur (feature engineering). Saat ini, sedang berkembang teknik deep learning yang tidak melakukan rekayasa fitur sama sekali. Pembelajaran mesin dapat diproses hanya dengan pasangan token dan labelnya. Deep learning merepresentasikan setiap token berupa vektor bobot yang didapatkan dari model semantik terdistribusi (word embedding) seperti word2vec atau glove.

Makalah ini memanfaatkan library anaGo yang merupakan implementasi Keras untuk sequence labeling (Lample dkk, 2016). Model ekstraksi event dibangun dengan menggunakan arsitektur bidirectional LSTMs (long short term memory) dan CRF (conditional random fields). Bi-LSTMs merupakan salah satu topologi deep learning yang berbasis jaringan syaraf tiruan atau artificial neural network (ANN). Setiap token direpresentasikan dengan model semantik terdistribusi berbasis karakter dan kata. Lample dkk (2016) mengembangkan model sequence labeling terbaik untuk NER (named-entity recognition) dalam 4 bahasa. Pada Gambar 4, ditunjukkan arsitektur Bi-LSTMs dan CRF yang diimplementasikan anaGo. Dalam mengaplikasikan library anaGo untuk ektraksi event $5 \mathrm{~W} 1 \mathrm{H}$, set kelas diidentifikasi dari training data, character embedding dibangun otomatis dari training data, token direpresentasikan sebagai vektor fitur hasil konkatenasi embedding karakter dan embedding kata, lalu bobot model Bi-LSTMs dan CRF ditentukan berdasarkan training data (anaGo, 2018; Lample dkk, 2016). 


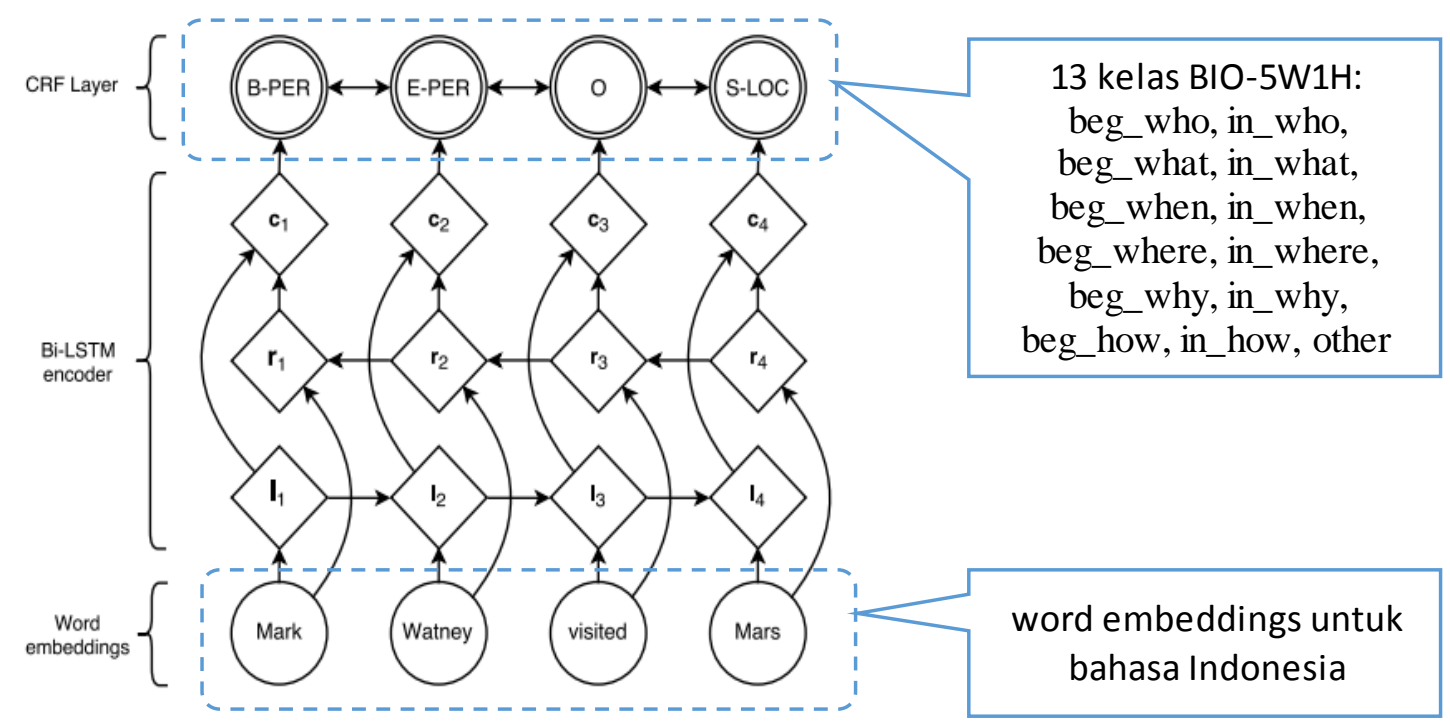

Gambar 4. Arsitektur Bi-LSTMs dan CRF untuk ekstraksi NER yang diaplikasikan untuk ekstraksi event (Lample dkk, 2016)

\section{HASIL DAN PEMBAHASAN}

Korpus untuk pemodelan ekstraksi event $5 \mathrm{~W} 1 \mathrm{H}$ berupa 57 artikel online berita politik yang terdiri dari 443 paragraf. Dalam korpus ini, digunakan istilah teks paragraf yang dianggap annotator memiliki satu topik pikiran. Beberapa paragraf yang terdiri dari satu kalimat dapat digabung menjadi satu teks paragraf, dan satu paragraf dapat displit menjadi beberapa teks paragraf. Dari 57 artikel, didapatkan 610 teks paragraf (610 sekuens token) dengan total 16.352 token.

Berdasarkan jumlah artikel berita, korpus dibagi menjadi 3 dataset yaitu training data (pembelajaran), data validasi, dan data tes. Seperti yang dibahas sebelumnya, training data digunakan untuk membangun model character embedding, dan melakukan update bobot model LSTMs dan CRF. Data validasi digunakan untuk menentukan konfigurasi yang dianggap dapat menghasilkan kinerja model terbaik, seperti jumlah epoch untuk berhenti. Data tes digunakan untuk menentukan kinerja model yang dihasilkan dalam pembelajaran. Tabel 1 menunjukkan komposisi data untuk 3 dataset, sedangkan Tabel 2 menunjukkan komposisi jumlah token untuk 3 dataset tersebut.

Tabel 1. Komposisi data: training, validasi, dan tes

\begin{tabular}{|l|r|r|r|r|}
\hline & \multicolumn{1}{|l|}{ Training } & Validasi & Tes & \multicolumn{1}{l|}{ Total } \\
\hline Artikel berita & 47 & 5 & 5 & 57 \\
\hline Paragraf & 367 & 40 & 36 & 443 \\
\hline Teks paragraf & 505 & 62 & 43 & 610 \\
\hline
\end{tabular}

Berbeda dengan hasil $5 \mathrm{~W} 1 \mathrm{H}$ dari satu artikel, hasil $5 \mathrm{~W} 1 \mathrm{H}$ dari satu paragraf sebagian besar hanya mengandung informasi what dan who. Berdasarkan korpus 5W1H dari 505 teks paragraf dari 47 artikel berita yang dianotasi manual, $77.3 \%$ dari 13.414 token merupakan token what dan who. Label Iwhat memiliki jumlah token terbanyak, sedangkan B-how yang paling sedikit tokennya.

Seperti yang ditunjukkan oleh Tabel 2, dataset pembelajaran yang diproses merupakan dataset yang tidak seimbang (imbalanced dataset). Persoalan dataset yang tidak seimbang membuat hasil klasifikasinya lebih cenderung untuk menghasilkan label dari kelas mayoritas. Kinerja model terbaik terhadap data tes adalah F1 0.62. Selain isu imbalanced dataset, korpus berlabel yang dikembangkan masih terlalu kecil ukurannya. 
Tabel 2. Komposisi token untuk training, validasi, dan tes

\begin{tabular}{|l|r|r|r|r|r|r|r|r|}
\hline \multirow{2}{*}{ Token BIO } & \multicolumn{2}{|c|}{ Training } & \multicolumn{2}{|c|}{ Validasi } & \multicolumn{2}{|c|}{ Tes } & \multicolumn{2}{|c|}{ Total } \\
\cline { 2 - 9 } & Frek & \multicolumn{1}{c|}{$\%$} & Frek & \multicolumn{1}{c|}{$\%$} & Frek & \multicolumn{1}{c|}{$\%$} & Frek & $\%$ \\
\hline Token B-who & 470 & $3.50 \%$ & 57 & $3.74 \%$ & 42 & $2.97 \%$ & 569 & $3.48 \%$ \\
\hline Token I-who & 1459 & $10.88 \%$ & 159 & $10.44 \%$ & 93 & $6.57 \%$ & 1711 & $10.46 \%$ \\
\hline Token B-what & 495 & $3.69 \%$ & 63 & $4.14 \%$ & 43 & $3.04 \%$ & 601 & $3.68 \%$ \\
\hline Token I-what & 7957 & $59.32 \%$ & 821 & $53.91 \%$ & 879 & $62.12 \%$ & 9657 & $59.06 \%$ \\
\hline Token B-when & 62 & $0.46 \%$ & 4 & $0.26 \%$ & 4 & $0.28 \%$ & 70 & $0.43 \%$ \\
\hline Token I-when & 204 & $1.52 \%$ & 25 & $1.64 \%$ & 11 & $0.78 \%$ & 240 & $1.47 \%$ \\
\hline Token B-where & 85 & $0.63 \%$ & 21 & $1.38 \%$ & 4 & $0.28 \%$ & 110 & $0.67 \%$ \\
\hline Token I-where & 349 & $2.60 \%$ & 68 & $4.46 \%$ & 12 & $0.85 \%$ & 429 & $2.62 \%$ \\
\hline Token B-why & 25 & $0.19 \%$ & 4 & $0.26 \%$ & 7 & $0.49 \%$ & 36 & $0.22 \%$ \\
\hline Token I-why & 382 & $2.85 \%$ & 60 & $3.94 \%$ & 131 & $9.26 \%$ & 573 & $3.50 \%$ \\
\hline Token B-how & 11 & $0.08 \%$ & 1 & $0.07 \%$ & 1 & $0.07 \%$ & 13 & $0.08 \%$ \\
\hline Token I-how & 189 & $1.41 \%$ & 8 & $0.53 \%$ & 7 & $0.49 \%$ & 204 & $1.25 \%$ \\
\hline Token O & 1726 & $12.87 \%$ & 232 & $15.23 \%$ & 181 & $12.79 \%$ & 2139 & $13.08 \%$ \\
\hline Total & 13414 & $100.00 \%$ & 1523 & $100.00 \%$ & 1415 & $100.00 \%$ & 16352 & $100.00 \%$ \\
\hline
\end{tabular}

Dengan model terbaik hasil pembelajaran, dapat dilakukan ekstraksi event 5W1H. Sebagai contoh, jika dimasukkan teks "PDIP yang dikawal Megawati menang dalam Pilkada DKI Jakarta", akan dihasilkan informasi who "PDIP yang dikawal Megawati" dan what "menang dalam Pilkada DKI Jakarta".

\section{KESIMPULAN \& SARAN}

Makalah ini mengembangkan model ekstraksi event $5 \mathrm{~W} 1 \mathrm{H}$ sebagai kegiatan sequence labeling dengan 13 label berskema BIO (Begin Inside Outside). Model ekstraksi event 5W1H merupakan hasil dari aplikasi library anaGo yang mengimplementasikan deep learning Keras dengan arsitektur Bi-LSTMs dan CRF berdasarkan 13.414 token yang menghasilkan model dengan kinerja F1 0.62.

Walaupun telah berhasil mengembangkan model ekstraksi event $5 \mathrm{~W} 1 \mathrm{H}$, masih terdapat persoalan ukuran korpus yang kecil dan imbalanced dataset. Penambahan ukuran korpus sangat potensial untuk meningkatkan kinerja model, dan penanganan imbalanced dataset dapat membantu mengekstraksi label minoritas seperti B-how dan I-how.

\section{DAFTAR PUSTAKA}

APJII. 2013. Statistik Indonesia Internet Users.

anaGo. 2018. Bidirectional LSTM-CRF for Sequence Labeling. https://github.com/Hironsan/anago

Graber, D. 1984. Processing the news: How people tame the information tide. New York: Longman.

Jiang, J. 2012. Information Extraction from Text, in Mining Text Data. Springer.

Khodra, M. L. 2015. Event extraction on Indonesian news article using multiclass categorization. In Advanced Informatics: Concepts, Theory and Applications (ICAICTA), 2015 2nd International Conference on (pp. 1-5). IEEE.

Lample, G., Ballesteros, M., Subramanian, S., Kawakami, K., \& Dyer, C. 2016. Neural architectures for named entity recognition. arXiv preprint arXiv:1603.01360.

Wang, W. 2012. Chinese News Event 5W1H Semantic Elements Extraction for Event Ontology Population, World Wide Web ACM Conference, Lyon.

RIWAYAT HIDUP/CURRICULUM VITAE

\begin{tabular}{|l|l|l|l|}
\hline $\begin{array}{c}\text { Nama Lengkap/ } \\
\text { Complete Name }\end{array}$ & \multicolumn{1}{|c|}{$\begin{array}{c}\text { Institusi/ } \\
\text { Institution }\end{array}$} & \multicolumn{1}{c|}{$\begin{array}{c}\text { Pendidikan/ } \\
\text { Education }\end{array}$} & $\begin{array}{c}\text { Minat Penelitian/ Research } \\
\text { Interests }\end{array}$ \\
\hline Masayu Leylia Khodra & ITB & S3 & $\begin{array}{l}\text { Linguistik Komputasional, } \\
\text { Pembelajaran Mesin, } \\
\text { Inteligensi Buatan }\end{array}$ \\
\hline Yudi Wibisono & UPI & S3 & Linguistik Komputasional \\
\hline
\end{tabular}


